\title{
Research on Harmonics and Ripple Content in Vector Control Schemes for Induction Motor
}

\author{
M.Rama Prasad Reddy, T.Sudhakar Babu, A.Suresh Kumar,U.Chaitanya
}

\begin{abstract}
- on this paper 3 considered one in every of a type vicinity based totally vector manage plans are enlisted for the assessment of the track and swell substance texture inside the engine flows and reliable kingdom torque waveforms. the interest in those vector oversee plans is, the reference flows are produced is as on the subject of ordinary vector control and selection of the voltage vectors is as almost about coordinate torque oversee. So the ones vector manipulate plans be part of the requirements of both conventional vector oversee and direct torque manage. the ones plans are confirmed within the MATLAB/Simulink scenario and the consequences are as concept approximately amongst them.

Watchwords-FOC, DTC, Induction engine, exchanging table, vector manage
\end{abstract}

\section{INTRODUCTION}

The gifted one within the cutting-edge pressure engine is popularity engine because it were. that is because of its much less assist and low weight volume share. From the preceding four many years many variety of controlling methods were proposed for the enlistment engine manipulate sports. among those the scalar manipulate method is giving the sluggish reaction, to conquer those complexities associated with the scalar control ordinary FOC become proposed in [1]. The FOC gives quick and dynamic transient response because of the decoupled control of transition and torque. Be that as it may, there is a downside on this FOC likewise that is the reference define modifications. To decrease the unpredictability engaged with the FOC the DTC was proposed in [2]. further, to build the adequacy of these manipulate systems staggered sustained acceptance engines are applied. A correlation amongst DTC and FOC of stage strengthened enlistment engine drive changed into talked about in [3]. Later couple of control strategies that are applied for the misfortune advancement methods of FOC of IM force [4]. some other manner with brief and dynamic calculation is proposed in [5] with LabVIEW. The ever calculation technique SVM based totally inverter interest with 8 switches is proposed in [6] with the traditional FOC method simply, yet the replacing of the inverter activates complicated calculation. In [7], a close to file on various adjustment strategies for the FOC changed into proposed. each this kind of strategies applied the fast and dynamic calculation frameworks.

\footnotetext{
Revised Manuscript Received on July 18, 2019.

M.Rama Prasad Reddy, EEE Department, G.Pullaiah College of Engineering and Technology, A.P., India.

T.Sudhakar Babu, EEE Department, G.Pullaiah College of Engineering and Technology, A.P., India

A.Suresh Kumar, EEE Department, G.Pullaiah College of Engineering and Technology, A.P., India

U.Chaitanya, EEE Department, G.Pullaiah College of Engineering and Technology, A.P., India
}

To overcome the downsides of ordinary vector control calculation and to lessen the calculation problem at the processors, in this paper, in this paper three notable territory fundamentally primarily based vector control plans are applied for the examination of the tune and swell substance in the engine flows and normal kingdom torque waveforms. the freshness in

The ones vector oversee plans is, the reference flows are produced is as in understanding to everyday vector manipulate and desire of the voltage vectors is as in undertaking with direct torque oversee. So the ones vector manipulate plans consolidate the fashions of every customary vector control and direct torque oversee.

\section{CLASSICAL QUARTER ORIENTATED MANAGE}

Within the Classical hassle oriented manage strategy the decoupling manipulate a massive quantity of the torque and motion is gotten with the precious asset of moving most people of the quantities to a synchronous reference frame. so the torque trouble iqs* and the transition fabricating aspect ids* is created with the manual of stator front line vector is*. anyway in mild of the decoupled manage the appealing influenza brought on the whole with q-pivot is zero. by techniques for method for this the electromagnetic torque condition is modified as

$$
T_{e}=\frac{3}{2} \frac{P}{2} \frac{L_{m}}{L_{r}}\left(\psi_{d r} i_{q s}\right)
$$

In this paper the main attention is focused on rotor flux angle calculation. This rotor flux angle calculated from (2).

$\theta_{s}=\theta_{r}+\theta_{s l}=\int\left(\omega_{r}+\omega_{s l}\right) d t$

Where $\omega_{s l}=\frac{L_{m} R_{r}}{L_{r} \lambda_{r}} i_{q s}^{*}$

Proposed Vector control methods

The electromagnetic torque of an induction motor is expressed as

$$
T_{e}=\frac{3}{2} \frac{P}{2} \frac{L_{m}}{L_{r}}\left|\bar{\lambda}_{r}\right|\left|\bar{i}_{s}\right| \sin \delta
$$




\section{RESEARCH ON HARMONICS AND RIPPLE CONTENT IN VECTOR CONTROL SCHEMES FOR INDUCTION MOTOR}

In which is the factor of view among and . as a result, a short control on torque might be completed by way of techniques for manner of controlling the factor anyway due to the widespread idleness of rotor circuit; the version within the rotor transition is practically reliable for a fast time intervening time. accordingly from the condition (three) the torque may be restrained by using converting over the stator cutting area angle. this will be achieved through way of changing the stator carry voltage. From the above situation the stator reducing part vector got as

$$
\Delta \bar{i}_{s}=\frac{1}{\sigma L_{s}} \bar{v}_{s} \Delta t
$$

By means of choosing the precise voltage vector it's miles then viable to alternate stator contemporary in required way. for this reason the decoupling manipulate may be carried out among ids and iqs additives of the stator modern-day vector.

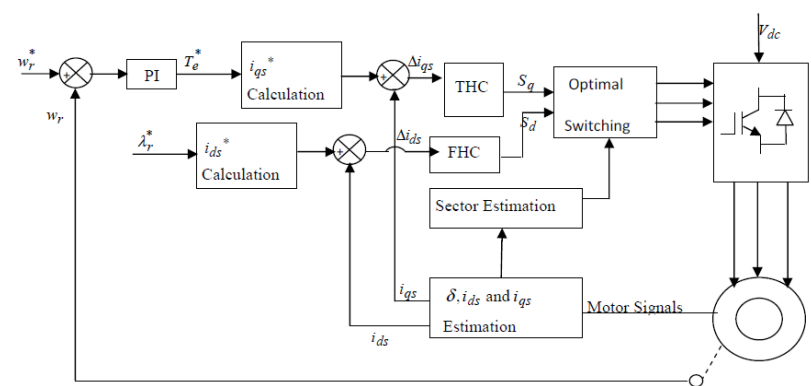

Fig.1. Block diagram of proposed vector controlled induction motor drive

The square graph of the predicted vector manage set of guidelines is as analyzed in Fig. 1. in the expected oversee method, the reference stator slicing side components are at synchronously pivoting reference outline. the ones are altogether created through the usage of the usual of normal vector manage set of recommendations. At that factor, inside the anticipated manage hysteresis comparators are utilized for torque and motion control. with the high-quality useful useful precious asset of taking the reference stator present dayday-day segments and actual stator modern parts, the mistake the front line day signs and indications and facet effects and signs and side results and symptoms are delivered. those blunders cutting edge signs and symptoms and symptoms and side effects and signs and symptoms and manifestations and signs and side consequences and symptoms and indicators and signs and side effects is probably given to the torque hysteresis comparator (THC) and transition hysteresis comparator (FHC). the ones hysteresis comparators will create the digitized yields based totally absolutely clearly past query honestly for the most component on the combination-up sizes. based at the digitized yields of the hysteresis comparators and normal for the stator present day-day (so that you can provide region assortment), the proper voltage vector are settled on a super method to preserve the blunder esteems in the evaluated data transmission of the hysteresis comparators.those notable voltage vectors may be helpful to the voltage supply inverter sustained enlistment engine stress.

A. Six location essentially based actually definitely Vector oversee The practicable voltage vectors for a 2degree inverter may be spoken to as inspected in Fig.

three, which incorporates six exuberant states and 0 states. on the equivalent time as, the isis within the major locale as tried in Fig.three, at that factor voltage vectors V2 and V6 can development the ids and V3 and V5 can deliver down the ids. further V2 and V3 can enlarge the torque factor contemporary-day-day iqs and V5 and V6 can convey down the iqs what's greater the excellent voltage vectors can be settled on for specific components. on this procedure, the cutting edge botches sizes are restricted to 2Dids and 2Diqs internal their separate hysteresis businesses. on the off hazard that enlargement in ids is required, at that factor $\mathrm{Sd}=1$; within the event that discount in ids is needed, at that factor $\mathrm{Sd}=$ zero . moreover, if increment in iqs is

required then $\mathrm{Sq}=1$, within the event that reduction in iqs is needed, at that factor $\mathrm{Sq}=-1$, and at the off threat that no exchange iqs is needed, at that factor $\mathrm{Sq}=$ zero. The virtual yield cautions from movement difficulty hysteresis controller (FHC) and torque inconvenience hysteresis controller (THC) is probably abridged as in desk. 1.

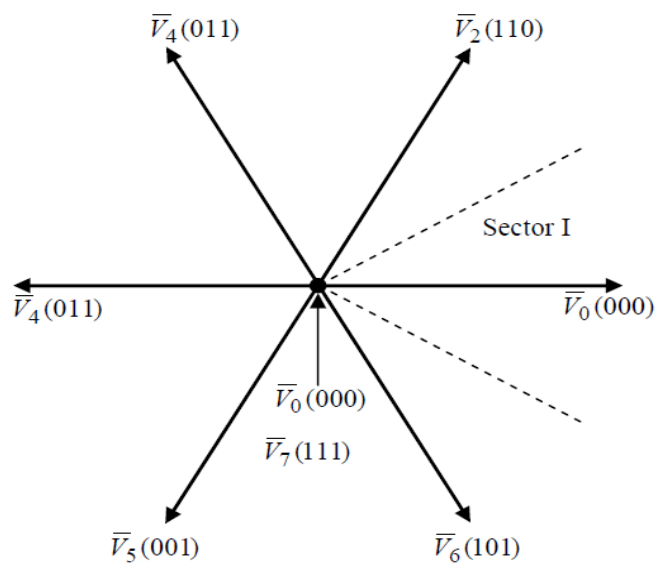

Fig. 2 Possible voltage space vectors for VSI

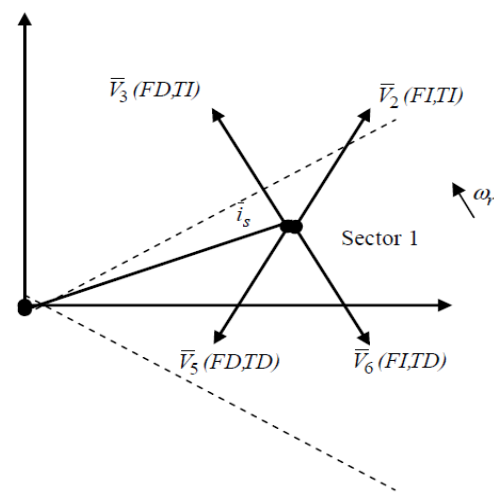

Fig. 3 selection of suitable voltage space vector insector $I\left(-30^{0}\right.$ to $\left.30^{\circ}\right)$ 
Table. 1 digitized output values of the hysteresis controllers

\begin{tabular}{|l|l|l|}
\hline Controller & Condition & $\begin{array}{l}\text { Output of the } \\
\text { controller }\end{array}$ \\
\hline \multirow{4}{*}{ FHC } & $\bar{i}_{d s} \leq \bar{i}_{d s}^{*}-\Delta \bar{i}_{s}$ & $S_{d}=1$ \\
\cline { 2 - 3 } & $\bar{i}_{d s} \geq \bar{i}_{d s}^{*}+\Delta \bar{i}_{s}$ & $S_{d}=0$ \\
\hline \multirow{5}{*}{ THC } & For anti-clockwise rotation \\
\cline { 2 - 3 } & $\bar{i}_{q s}^{*}-\bar{i}_{q s} \geq \Delta \bar{i}_{q s}$ & $S_{q}=1$ \\
\cline { 2 - 3 } & $\bar{i}_{q s} \geq \bar{i}_{q s}^{*}$ & $S_{q}=0$ \\
\cline { 2 - 3 } & For clockwise rotation \\
\cline { 2 - 3 } & $\bar{i}_{q s} \leq \bar{i}_{q s}^{*}$ & $S_{q}=0$ \\
\cline { 2 - 3 } & $\bar{i}_{q s}^{*}-\bar{i}_{q s} \leq-\Delta \bar{i}_{q s}$ & $S_{q}=-1$ \\
\hline
\end{tabular}

Fundamentally dependent on the estimations of $\mathrm{Sd}$ ,sq.and the situation of the stator current vector, the perfect voltage vector is chosen from the investigations work area as given in table. 2.

B. 12-division based absolutely totally Vector control in the 6-locale based vector control, best an incomplete state of vigorous voltage vectors are utilized each region. a top notch approach to use each of the six vivacious states in each locale and to reduce the THD what's more, the space vector flying machine is isolated into twelve parts in decision to 6 as affirmed in Fig. four. however, it's miles required to give a reason to little and huge deviations. it is seen that V1 will deliver an enormous increment in motion and a little development in torque in zone-12. as a substitute it is discovered that V2 will create an enormous addition in torque and a little augmentation in motion. The anticipated 12-zone essentially based vector oversee rehearses a four phase torque hysteresis controller (TI: torque development, TSI: torque little development, TD: torque abatement and TSD: torque little cut cost) and a level motion hysteresis controller. the appearance up work area for 12-zone based absolutely FOC is realistic in table 3.

Table. 2 Optimum voltage vector switching table for 6-sector based vector control

\begin{tabular}{|c|c|c|c|c|c|c|c|}
\hline \multicolumn{2}{|c|}{ Sectors } & I & II & III & IV & V & VI \\
\hline Sd & Sq & & & & & & \\
\hline \multirow{4}{*}{$\mathbf{1}$} & $\mathbf{1}$ & $\overline{V_{2}}$ & $\overline{V_{3}}$ & $\overline{V_{4}}$ & $\overline{V_{5}}$ & $\overline{V_{6}}$ & $\overline{V_{1}}$ \\
\cline { 2 - 8 } & $\mathbf{0}$ & $\overline{V_{7}}$ & $\overline{V_{0}}$ & $\overline{V_{7}}$ & $\overline{V_{0}}$ & $\overline{V_{7}}$ & $\overline{V_{0}}$ \\
\cline { 2 - 8 } & $\mathbf{- 1}$ & $\bar{V}_{6}$ & $\overline{V_{1}}$ & $\overline{V_{2}}$ & $\overline{V_{3}}$ & $\overline{V_{4}}$ & $\overline{V_{5}}$ \\
\hline \multirow{4}{*}{$\mathbf{0}$} & $\mathbf{1}$ & $\overline{V_{3}}$ & $\overline{V_{4}}$ & $\overline{V_{5}}$ & $\overline{V_{6}}$ & $\overline{V_{1}}$ & $\overline{V_{2}}$ \\
\cline { 2 - 8 } & $\mathbf{0}$ & $\overline{V_{0}}$ & $\overline{V_{7}}$ & $\overline{V_{0}}$ & $\overline{V_{7}}$ & $\overline{V_{0}}$ & $\overline{V_{7}}$ \\
\cline { 2 - 8 } & $\mathbf{- 1}$ & $\overline{V_{5}}$ & $\overline{V_{6}}$ & $\overline{V_{1}}$ & $\overline{V_{2}}$ & $\overline{V_{3}}$ & $\overline{V_{4}}$ \\
\hline
\end{tabular}

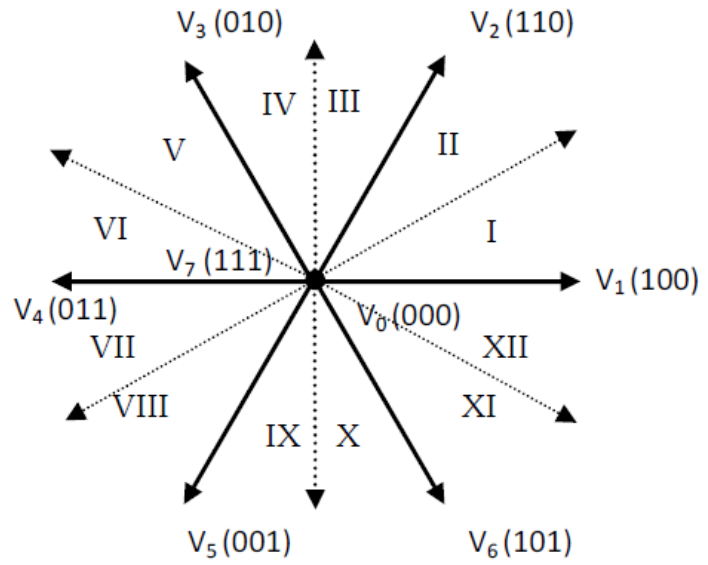

Fig. 4 Possible voltage space vectors for VSI in 12sector based vector control algorithm

C. 24-place basically primarily based Vector oversee to diminish the THD improvement, on this paper a 24-locale basically based totally vector manipulate set of regulations has been anticipated. in this technique the distance vector air deliver is a component into 24 regions as permitted in Fig. five. in this framework, just like the 6-segment primarily based surely thoroughly manage method, the bleeding area botches extents are restrained to twodids and more than onediqs interior their person hysteresis groups. in the 24-region manipulate, 3-arrange hysteresis controllers are utilized for d-and q-tomahawks current controllers. The arrangement of the 3-diploma hysteresis controller is related to that of q-pivot modernday controller of 6-location based totally honestly vector oversee calculation.

Table. 3 Optimum voltage vector switching table for 12-sector based vector control

\begin{tabular}{|c|c|c|c|c|c|c|c|c|c|c|c|c|}
\hline$S$ & $S_{q}$ & \begin{tabular}{|l|l}
$\mathrm{S}_{1}$ & $\mathrm{~S}_{2}$
\end{tabular} & $\mathrm{~S}_{3}$ & $\mathrm{~S}_{4}$ & $S_{5}$ & 6 & 7 & 8 & & $\mathrm{~S}_{10}$ & & $S_{12}$ \\
\hline & TI & $\bar{V}_{2} \mid \bar{V}_{3}$ & $\bar{V}_{3}$ & $\bar{V}_{4}$ & $\bar{V}_{4}$ & $\overline{V_{5}}$ & $\bar{V}_{5}$ & 6 & $V_{6}$ & $\bar{V}_{1}$ & & $\bar{V}_{2}$ \\
\hline & TsI & \begin{tabular}{|l|l|}
$\bar{V}_{2}$ & $\bar{V}_{2}$
\end{tabular} & $\bar{V}_{3}$ & $\bar{V}_{3}$ & $\bar{V}_{4}$ & $\bar{V}_{4}$ & $\bar{V}_{5}$ & $\bar{V}_{5}$ & $\bar{V}_{6}$ & $\bar{V}_{6}$ & & $\bar{V}_{1}$ \\
\hline & $\mathrm{TsD}$ & \begin{tabular}{|l|l|}
$\bar{V}_{1}$ & $\bar{V}_{1}$
\end{tabular} & $\bar{V}_{2}$ & $\bar{V}_{2}$ & $\bar{V}_{3}$ & $\bar{V}_{3}$ & $\bar{V}_{4}$ & $\bar{V}_{4}$ & $\bar{V}_{5}$ & $\bar{V}_{5}$ & & $\bar{V}_{6}$ \\
\hline & TD & $\bar{V}_{6} \mid \bar{V}_{1}$ & $\bar{V}_{1}$ & $\bar{V}_{2}$ & $\bar{V}_{2}$ & $\bar{V}_{3}$ & $\bar{V}_{3}$ & $\bar{V}_{4}$ & $\bar{V}_{4}$ & $\bar{V}_{5}$ & 5 & $\bar{V}_{6}$ \\
\hline & TI & $\bar{V}_{3} \bar{V}_{4}$ & $\bar{V}_{4}$ & $\bar{V}_{5}$ & $\bar{V}_{5}$ & $V_{6}$ & $\overline{V_{6}}$ & $\bar{V}_{1}$ & $\bar{V}_{1}$ & $\bar{V}_{2}$ & 2 & $V_{3}$ \\
\hline & $\mathrm{TsI}$ & \begin{tabular}{|l|l|}
$\bar{V}_{4}$ & $\bar{V}_{4}$
\end{tabular} & $\bar{V}_{5}$ & $\bar{V}_{5}$ & $\bar{V}_{6}$ & $V_{6}$ & $V_{1}$ & $\bar{V}_{1}$ & $V_{2}$ & $V_{2}$ & 3 & 3 \\
\hline & $\mathrm{TsD}$ & \begin{tabular}{|l|l|l}
$\bar{V}_{7}$ & $\bar{V}_{5}$
\end{tabular} & $\bar{V}_{0}$ & $\bar{V}_{6}$ & $\bar{V}_{7}$ & $\bar{V}_{1}$ & $\bar{V}_{0}$ & $\bar{V}_{2}$ & $\bar{V}_{7}$ & $\bar{V}_{3}$ & 0 & $V_{4}$ \\
\hline & TD & \begin{tabular}{|l|l|}
$\bar{V}_{5}$ & $\bar{V}_{6}$
\end{tabular} & $\bar{V}_{6}$ & $\bar{V}_{1}$ & $\bar{V}_{1}$ & $\bar{V}_{2}$ & 2 & & $\bar{V}_{3}$ & 4 & 4 & $\bar{V}_{5}$ \\
\hline
\end{tabular}




\section{RESEARCH ON HARMONICS AND RIPPLE CONTENT IN VECTOR CONTROL SCHEMES FOR INDUCTION MOTOR}

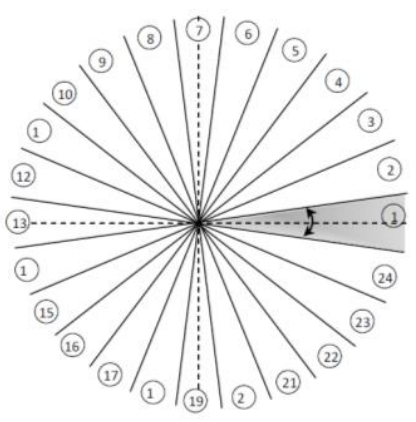

Fig. 5 Possible voltage space vectors for VSI in 24sector based vector control algorithm

Table.4 digitized output values of the hysteresis controllers

\begin{tabular}{|l|l|l|}
\hline Controller & Condition & $\begin{array}{l}\text { Output of the } \\
\text { controller }\end{array}$ \\
\hline \multirow{4}{*}{ FHC } & \multicolumn{2}{|l|}{ For anti-clockwise rotation } \\
\cline { 2 - 3 } & $\bar{i}_{d s}^{*}-\bar{i}_{d s} \geq \Delta \bar{i}_{d s}$ & $S_{q}=1$ \\
\cline { 2 - 3 } & $\bar{i}_{d s} \geq \bar{i}_{d s}^{*}$ & $S_{q}=0$ \\
\cline { 2 - 3 } & For clockwise rotation \\
\cline { 2 - 3 } THC & $\bar{i}_{d s} \leq \bar{i}_{d s}^{*}$ & $S_{q}=0$ \\
\cline { 2 - 3 } & $\bar{i}_{d s}^{*}-\bar{i}_{d s} \leq-\Delta \bar{i}_{d s}$ & $S_{q}=-1$ \\
\hline \multirow{5}{*}{} & For anti-clockwise rotation \\
\cline { 2 - 3 } & $\bar{i}_{q s}^{*}-\bar{i}_{q s} \geq \Delta \bar{i}_{q s}$ & $S_{q}=1$ \\
\cline { 2 - 3 } & $\bar{i}_{q s} \geq \bar{i}_{q s}^{*}$ & $S_{q}=0$ \\
\cline { 2 - 3 } & For clockwise rotation \\
\cline { 2 - 3 } & $\bar{i}_{q s} \leq \bar{i}_{q s}^{*}$ & $S_{q}=0$ \\
\cline { 2 - 3 } & $\bar{i}_{q s}^{*}-\bar{i}_{q s} \leq-\Delta \bar{i}_{q s}$ & $S_{q}=-1$ \\
& \multicolumn{2}{|l}{} \\
\hline
\end{tabular}

Based on the values of $S d$,Sqand sector number, the suitable voltage vector is selected from the lookup table as given in Table. 5 .

Table. 5 Optimum voltage vector switching table for 24-sector based vector control

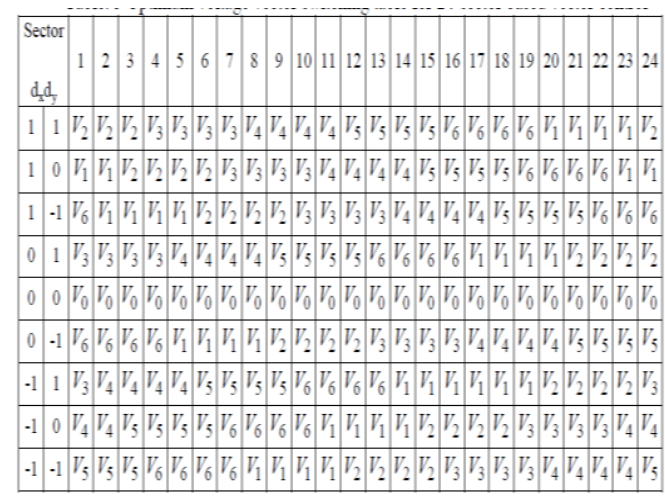

\section{SIMULATION IMPACTS AND TALK \& RESULTS}

To approve the anticipated examinations tables based absolutely totally point of fact vector control set of rules numerical recreation assessments were done through utilizing MATLAB. For the reproduction look into the engine parameters are taken as $\mathrm{Rs}=1.57 \omega, \mathrm{Rr}=1.21 \Omega$, $\mathrm{Lm}=$ zero. $165 \mathrm{H}, \mathrm{Ls}=0.17 \mathrm{H}, \mathrm{Lr}=0.17 \mathrm{H}$ and $\mathrm{J}=$ zero. 089 Kg-m2. also, for the reenactment results equivalent band widths have been estimated for the hysteresis groups inside the anticipated and blessing contemporary-day controlled vector oversaw drives. The recreation consequences of zone 6,12 and 24 vector oversaw acceptance engine stress are appeared in Fig.6Fig.sixteen. From the reproduction impacts, it could be seen that the 24 research table based absolutely totally vector control calculations offer quick concise response like customary vector control set of principles. and yet as contrasted and the 6 area activity the 12 and 24 area activity is demonstrating a more slow reaction. moreover, it could be found that the 12 and 24 - part set of tips gives bounty considerably less acclaimed symphonious contortion (THD) charge at the equivalent time as contrasted and the 6 place fundamentally based completely most likely vector oversee set of proposals for same band width of the hysteresis controllers. moreover, the 12 and 24-locale based really vector control set of recommendations gives steady exchanging recurrence activity on a similar time as related with the six area vector control set of proposals, which can be seen from the engine torque swell and speed waveforms. From the steady u .s .a . recreation results and consonant spectra of line flows, it could be situated that the anticipated 24 quarter query table based vector control set of guidelines offers diminished symphonious mutilation while in assessment with the inverse control calculations.

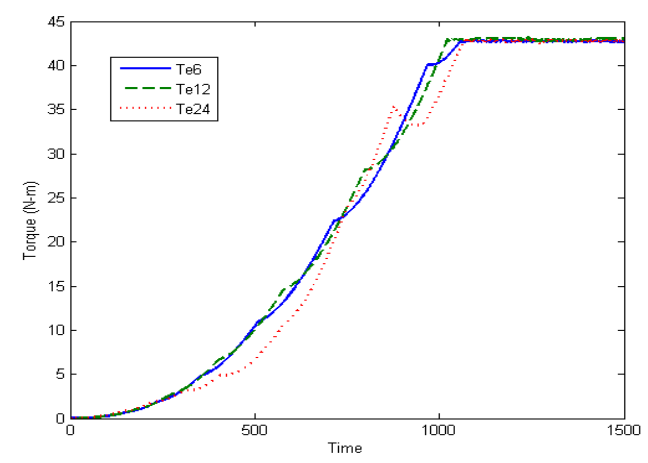

Fig. 6 Starting torque transients of 6, 12 and 24 sector based vector control.

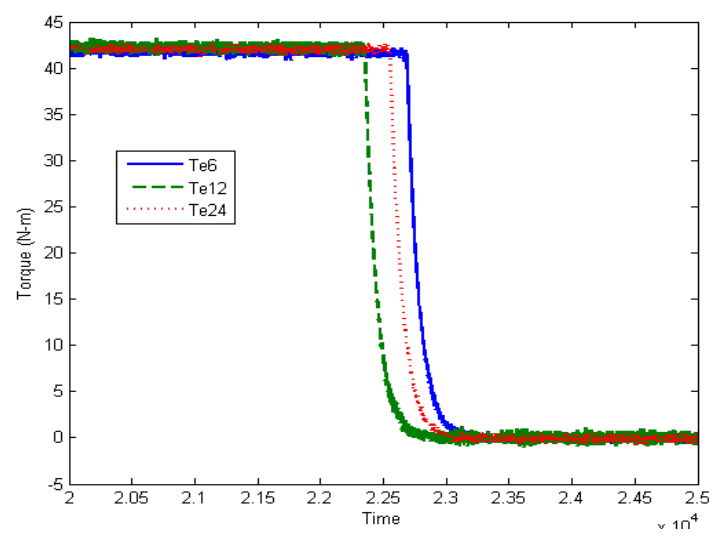

Fig. 7 Torque transients reaching the steady state of 6 , 12 and 24 sector based vector control 


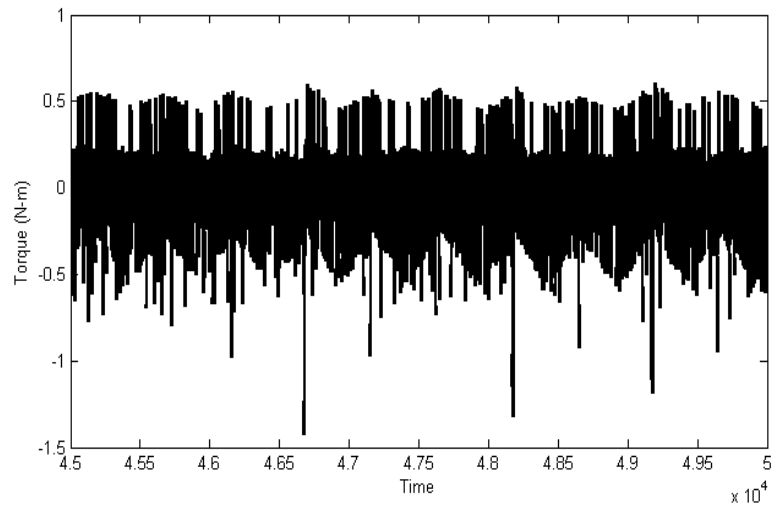

Fig. 8 Torque ripple during steady state (6 Sector)

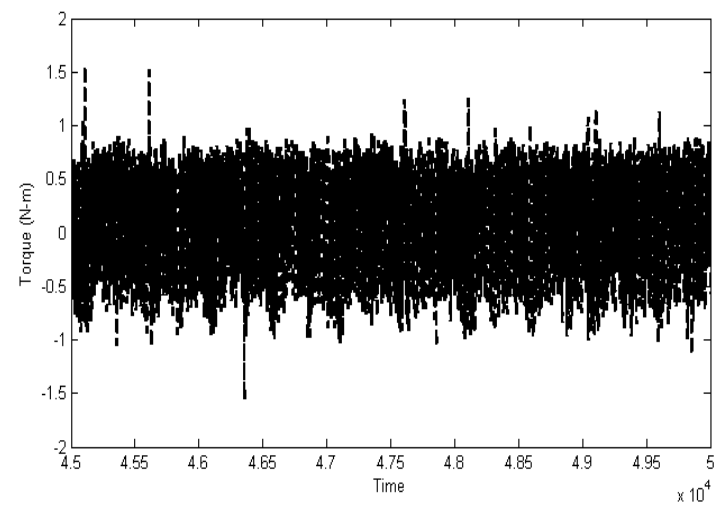

Fig. 9 Torque ripple during steady state (12 Sector)

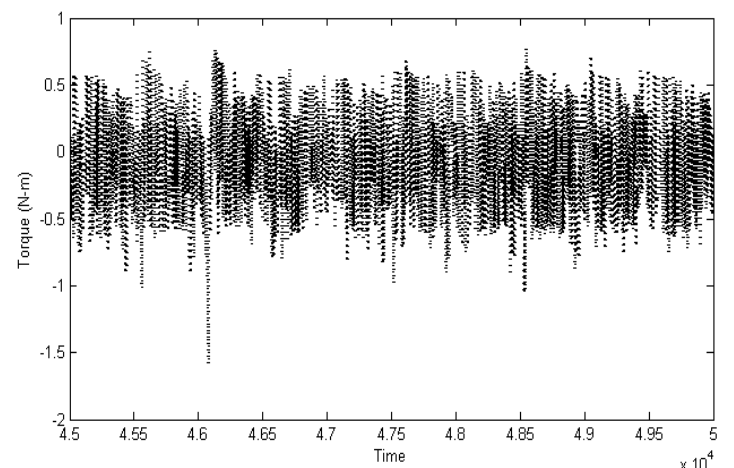

Fig. 10 Torque ripple during steady state (24 Sector)

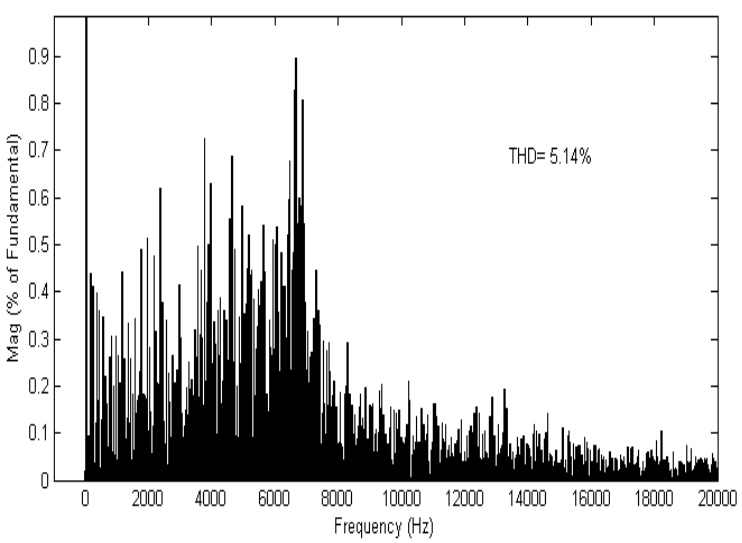

Fig. $11 \%$ THD of 6 Sector based voltage oriented control of induction motor



Fig. $12 \%$ THD of 12 Sector based voltage oriented control of induction motor

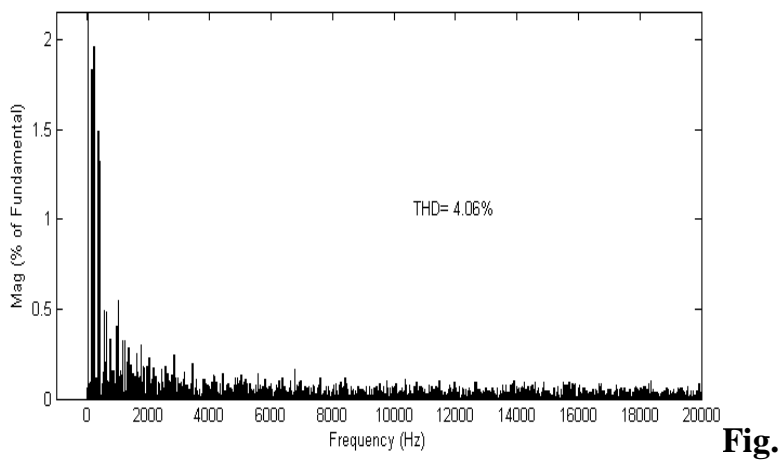

$13 \%$ THD of 24 Sector based voltage oriented control of induction motor

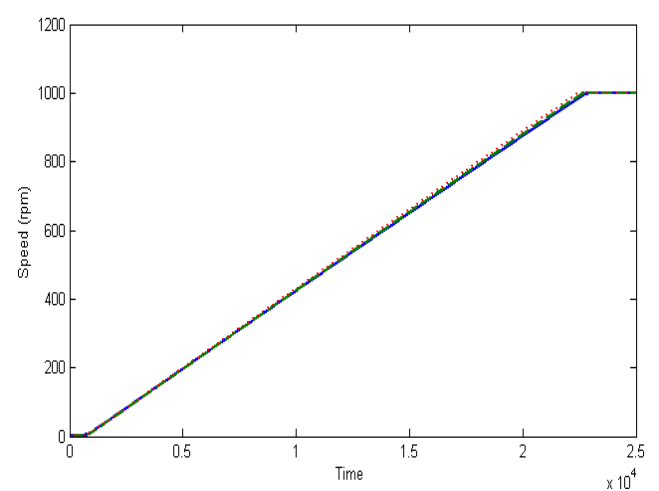

Fig. 14Speed curve of 6,12 and 24 Sector based voltage oriented control of induction motor

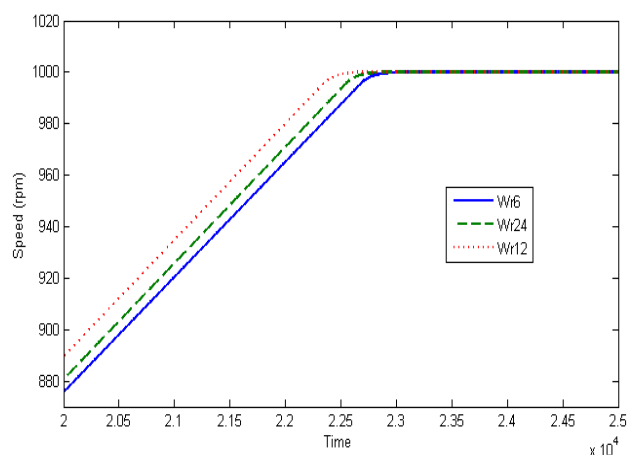

Fig. 15 Speed curve of 6, 12 and 24 Sector based voltage oriented control of induction motor reaching the rated speed

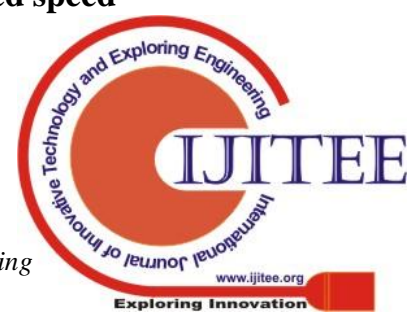



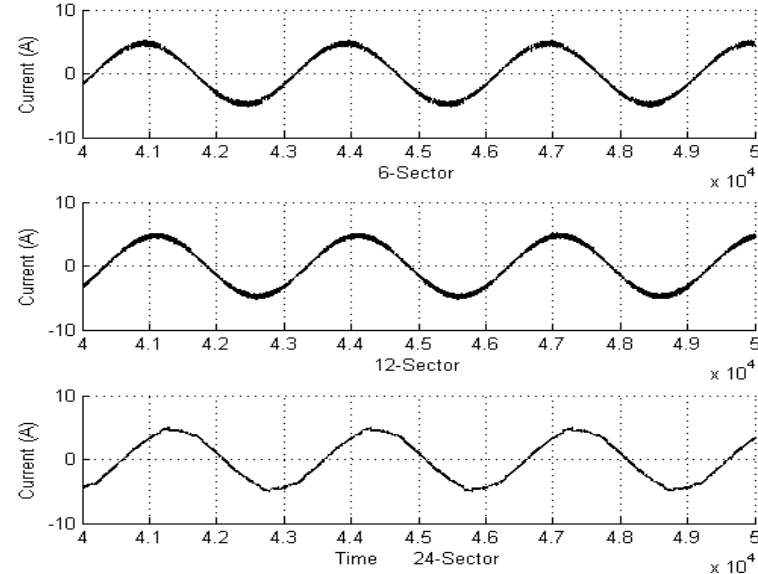

Fig. 16 Motor line currents of 6,12 and 24 Sector based voltage oriented control of induction motor during the steady state period.

\section{CONCLUSIONS}

A quite positive vector manage set of recommendations is offered on this paper, which blends the psyche of every vector manage and direct torque oversee. The predicted control makes use of hysteresis comparators and studies tables. to demonstrate the helpfulness of the changing tables based totally absolutely certainly vector manipulate set of recommendations, diverse exercise results are given and in evaluation. From the reproduction results, it tends to be put that the 24 studies tables basically based completely vector control contributes appropriate fast reaction with dwindled consonant bending and unpredictability concurrently as diagnosed with the open door vector oversee calculations.

\section{REFERENCES}

1. F. Blaschke, "the rule of area course as related to the new transvector close circle manipulate framework for pivoting area machines," Siemens assessment, 1972, pp 217-220.

2. Isao Takahashi, Toshihiko Noguchi, "another fast reaction and excessive-effectiveness control method of an attractiveness engine", IEEE Trans Ind Appl, Vol.IA-22, No.5, pp. 820-827, Sep/Oct, 1986.

3. U. V Patil, H. M. Suryawanshi, M. M. Renge, "Execution correlation of DTC and FOC recognition engine drive in five stage diode clasped inverter", IEEE-global convention On Advances In Engineering, technology And management (ICAESM - 2012),yr: 2012,page s: 227 - 230.

4. WahibaKhemiri ; Anis Sakly ; M. FaouziMimouni,"performance correlation for misfortune development methods of FOC attractiveness engine drive", 2015 IEEE twelfth global Multi-convention on structures, signals and devices (SSD15), yr: 2015, page s: 1 - 6.

5. Tao Wu ; Yi-Lin Chi ; Yu Guo ; Chao Xu,"Simulation of FOC Vector control of Induction Motor primarily based on LabVIEW", 2009 global conference on information Engineering and computer technology, 12 months: 2009, web page s: 1 - 3 .

6. Qidi Tang ; Xinglai Ge ; Yong-Chao Liu,"overall performance examination of various SVM-based fieldsituated manage plans for eight-switch 3-degree inverterreinforced enlistment engine drives", 2016 IEEE eighth international energy Electronics and movement manipulate convention (IPEMC-ECCE Asia), year: 2016, page s: 3374 $-3378$.

7. T. Banerjee ; J. N. Bera ; S. Chowdhuri ; G. Sarkar,"A comparable investigation between various tweaks approaches utilized in area organized manage recognition engine power", 2016 2d worldwide convention on manage, Instrumentation, energy and communique (CIEC), 12 months: 2016, web page s: 358 - 362 .

8. M.Rama Prasad Reddy, T. Brahmananda Reddy, Member, IEEE, B. Brahmaiah, " A circle of relatives of research Tables for Novel Vector controlled Induction Motor Drives" Acta 